\title{
OS CÍRCULOS DE CULTURA COMO POSSIBILIDADE PEDAGÓGICA NA PERSPECTIVA DA EMANCIPAÇÃO: UMA EXPERIÊNCIA NO PROEJA DE UMA ESCOLA PÚBLICA DE SALVADOR - BA, BRASIL
}

\author{
LOS CÍRCULOS DE CULTURA COMO POSIBILIDAD PEDAGOGICA EN LA \\ PERSPECTIVA DE LA EMANCIPACIÓN: UNA EXPERIENCIA EN EL PROEJA DE \\ UNA ESCUELA PÚBLICA DE SALVADOR - BA, BRASIL
}

\section{CULTURAL CIRCLES AS A PEDAGOGICAL POSSIBILITY IN THE EMANCIPATION PERSPECTIVE: AN EXPERIENCE IN THE PROEJA OF A PUBLIC SCHOOL OF SALVADOR - BA, BRAZIL}

\author{
Joana Lopes VIERA ${ }^{1}$ \\ Maria Cecília de Paula SILVA ${ }^{2}$
}

RESUMO: Este artigo é parte de uma pesquisa de doutorado e tem como objetivo tratar do círculo de cultura inserido na práxis pedagógica no Programa de Educação de Jovens e Adultos - PROEJA em uma escola pública de Salvador, Bahia Brasil. Buscamos a conceituação de Freire (1987) sobre círculos de cultura e Sousa Santos (2007) e Arroyo (2014), sobre a necessidade de propormos outras pedagogias que reconheçam "outros sujeitos", por meio de uma experiência pedagógica. Justifica-se pela importância dos círculos de cultura como proposta pedagógica que amplia a dimensão epistemológica por possibilitar a construção de novos conhecimentos, consubstanciada por possibilidades educacionais, diferentes da lógica hegemônica, baseada nos diálogos, reflexões e interações. Concluímos que os círculos de cultura nos possibilitaram realizar o exercício da consciência histórica, política e cultural, bem como afirmar a pertinência dos mesmos no fazer pedagógico para a educação de jovens e adultos.

PALAVRAS-CHAVE: Círculo de cultura. Educação. Emancipação. PROEJA.

RESUMEN: Este artículo es parte de una investigación doctoral y tiene como objetivo estudiar el círculo de la cultura insertado en la praxis pedagógica en el Programa de Educación de Jóvenes y Adultos - PROEJA en una escuela pública en Salvador, Bahia Brasil. Buscamos la conceptualización de Freire (1987) en círculos culturales y Sousa Santos (2007) y Arroyo (2014) sobre la necesidad de proponer otras pedagogías que reconozcan "otros temas" a través de una experiencia pedagógica. Se justifica por la importancia de los círculos culturales como una propuesta pedagógica que amplía la dimensión epistemológica al permitir la construcción de nuevos conocimientos, consolidados por posibilidades educativas, diferentes de la lógica

\footnotetext{
${ }^{1}$ Universidade Federal da Bahia (UFBA), Salvador - BA - Brasil. Doutoranda do Programa de Pós-graduação em Educação. Bolsista CNPq. Membro do Grupo de pesquisa HCEL. ORCID: <https://orcid.org/0000-0001-85749675>. E-mail: marialaranja@gmail.com

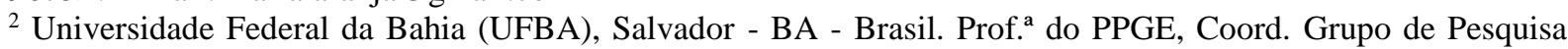
HCEL - CNPq. Coord. PPGE FACED UFBA 2017-19. Bolsista CAPES Processo BEX 6990/14-2. Estágio Sênior - Université de Strasbourg (2015-16). ORCID: 〈http://orcid.org/0000-0002-3506-8510>. E-mail: ceciliadepaula.ufba@gmail.com
} 
hegemónica, a partir de diálogos, reflexiones e interacciones. Concluimos que los círculos culturales nos han permitido llevar a cabo el ejercicio de la conciencia histórica, política y cultural, así como afirmar su pertinencia en la práctica pedagógica para la educación de jóvenes y adultos.

PALABRAS CLAVE: Círculo de cultura. Educación. Emancipación. PROEJA.

ABSTRACT: This article is part of a doctoral research and aims to study the circle of culture inserted in the pedagogical praxis in the Program of Education of Young and Adults - PROEJA in a public school in Salvador, Bahia Brazil. We seek the conceptualization of Freire (1987) on cultural circles and Sousa Santos (2007) and Arroyo (2014) on the need to propose other pedagogies that recognize "other subjects" through a pedagogical experience. It is justified by the importance of cultural circles as a pedagogical proposal that extends the epistemological dimension by enabling the construction of new knowledge, consubstantiated by educational possibilities, different from hegemonic logic, based on dialogues, reflections and interactions. We conclude that cultural circles have enabled us to carry out the exercise of historical, political and cultural awareness, as well as to affirm their pertinence in the pedagogical practice for the education of young people and adults.

KEYWORDS: Circle of culture. Education. Emancipation. PROEJA.

\section{Introdução}

No tempo presente a escola continua a produzir um modelo educativo que não é o único possível, mas que historicamente lhe foi atribuído. Freire (1987) denomina este modelo de "bancário", no qual o professor deposita o conhecimento e o estudante o recebe. Este modelo pode fomentar um ensino alienador típico da sociedade tecnocrata e mercantil, submissa ao poder ideológico, facilmente, entorpece professores (as) e educandos (as) perante uma conjuntura sociopolítica autoritária (GADOTTI, 2003).

No contexto específico da educação brasileira constatamos profundas desigualdades e contradições. É comum ouvirmos frases como esta, não se educa no Brasil! Em muitas práxis educativas constata-se uma escolha pela instrumentalização para o mercado de trabalho, em detrimento da escolha pela formação humana. Gadotti (2003) em seu estudo sobre a educação brasileira constata que o atual modelo educativo se baseia na ideologia da profissionalização e do desenvolvimento. Um modelo que propõe reformas direcionadas para a industrialização e modernização da educação com o objetivo de manter um sistema econômico e legitimar a concentração de renda e os meios de produção. Para este autor, apesar dos discursos oficiais do governo e das políticas públicas direcionadas para a educação, de forma geral, estamos longe 
de construir uma educação que promova um saber descolonizado, a criatividade e a transformação social.

Consideramos que existem outras possibilidades de fazer educação e, consequentemente, buscar por construir outra sociedade. Uma sociedade constituída por uma educação que conceba a mulher e o homem como 'seres integrais', capazes de se reconhecerem como sujeitos políticos e sociais que ao atuarem sobre a sua realidade, se compreendam como coparticipantes da história e criadores da sua própria história (FREIRE, 1987, 2014a).

Este artigo é parte de uma pesquisa de doutorado e tem como objetivo tratar do círculo de cultura inserido na práxis pedagógica no Programa de Educação de Jovens e Adultos PROEJA em uma escola pública de um quilombo urbano de Salvador, Bahia, Brasil. O Programa Nacional de Integração da Educação Profissional com a Educação Básica na Modalidade de Educação de Jovens e Adultos, denominado PROEJA é promovido pelo Governo Federal e surge em 2006 pelo Decreto $N^{\circ} 5.840$.

Este programa, inserido no âmbito de uma de política educacional mais ampla, objetiva proporcionar o acesso do público jovem e adulto ao ensino médio integrado por meio de uma educação profissional técnica, denominada Educação de Jovens e Adultos - EJA (BRASIL, 2007).

Como concepção política busca oferecer uma formação fundamentada na educação integral, a qual incluí as dimensões do trabalho, ciência, técnica, tecnologia, humanismo e cultura geral, bem como considerar as singularidades e características dos jovens e adultos (BRASIL, 2007).

Lima Filho (2010) compreende que esta modalidade de ensino possui um caráter estratégico e inovador, por buscar reduzir desigualdades sociais e fortalecer a cidadania, com ações que aumentem os níveis de escolarização e profissionalização. E, por este motivo, tornase promissora, embora seja necessário considerar os desafios políticos, epistemológicos e infraestruturais que revestem essa modalidade. Desafios relacionados tanto a necessidade de disponibilizar e adequar os recursos pedagógicos e metodológicos como garantir a formação de professores para esta modalidade.

Trabalhamos com a proposição pedagógica dos círculos de cultura a partir da conceituação de Freire (1987) e com Sousa Santos (2007) e Arroyo (2014) para a reflexão colocada em pratica no estudo, e aqui apresentada sobre a necessidade de refletirmos nossa práxis educativa e propormos outras pedagogias que reconheçam "outros sujeitos", por meio da experiência pedagógica. 
Freire (2014b, 1994) define o círculo de cultura como uma possibilidade de construir conhecimento e não, simplesmente uma metodologia de trabalho. $\mathrm{O}$ autor nos apresenta o círculo de cultura como uma forma de promover ações dialógicas sobre os fenômenos sociais a partir de uma perspectiva crítica e desestabilizadora. Este modo de fazer educação possibilita romper com a compreensão das "situações existenciais" e a consciência de si mesmo para uma situação de compreensão de si mesmo no meio social, o ser individual e coletivo de Gramsci (2001).

Esta proposição educativa justifica-se pela importância dos círculos de cultura como proposta pedagógica que amplia a dimensão epistemológica por possibilitar a construção de novos conhecimentos, consubstanciada por relações de ensinar e aprender. Experimentaram-se outras possibilidades educacionais, diferentes da lógica hegemônica, baseadas nos diálogos, reflexões e interações.

Detivemo-nos na experiência do círculo de cultura intitulado "Alike: educação, criatividade e transformação", dialogando com os educandos (as) do PROEJA e com a proposição de Santos (1996, 2007). Santos nos apresenta uma provocação a respeito do pensamento acadêmico hegemônico e nos instiga a agirmos, epistemológica e pedagogicamente, em uma perspectiva contra-hegemônica. Para tal ele nos propõe a trabalhar com imagens desestabilizadoras do passado histórico, para o surgimento de subjetividades rebeldes e indignadas pela desumanização verificada no tempo presente.

Esta experiência nos possibilitou realizar, para além do conhecimento pedagógico, o exercício da consciência histórica, política e cultural, bem como afirmar a pertinência dos círculos de cultura no fazer pedagógico para a educação de jovens e adultos. Concluímos que os círculos de cultura considerados em sua dimensão pedagógica, para além de uma proposta metodologia, podem oportunizar a criação de uma contra-hegemonia que produza outras pedagogias, outros sujeitos.

\section{Dos caminhos percorridos: do lugar, do ambiente do grupo e da experiência}

Tivemos a intenção de aprofundar a dinâmica teórica e práxis ${ }^{3}$ dos círculos de cultura, desenvolvida com um grupo de jovens e adultos de uma escola pública estadual de um quilombo urbano de Salvador, Brasil, realizada durante todo o ano de 2017. A escola possuiu uma ótima

${ }^{3}$ Os procedimentos empregados na pesquisa teórica e práxis estão de acordo com os princípios éticos, por isso os nomes das entrevistadas são fictícios e foram escolhidos por elas e, o nome do bairro e da escola pública não será revelado. 
infraestrutura, embora as suas instalações estejam em decadência no tempo presente. Localizada em um bairro central de Salvador, considerado um dos mais antigos e tradicionais da cidade.

Surge, no final do século XVI, de uma fazenda considerada, à época, um dos maiores latifúndios do Brasil. Esta fazenda se dedicava à agropecuária e ao comércio de mão-de-obra escravizada. Mais tarde, a terra foi propriedade de um Mosteiro, comprada por um grande proprietário de terras e, finalmente, por uma das famílias mais ricas da indústria fabril baiana. De grande propriedade privada o bairro é criado após a crise econômica da União Fabril no início do século XX, em que partes da fazenda foram arrendadas pelos trabalhadores da fábrica e por migrantes (SANTOS, 2007a). A escola situa-se no lugar em que, noutros tempos, era a portaria da fazenda.

Neste ponto chama-se a atenção do sentido estabelecido por lugar, neste texto. Augé (2012, p. 51) apresenta-nos diversas definições de lugar, entre eles, o lugar antropológico que "é simultaneamente princípio de sentido para aqueles que o habitam e princípio de inteligibilidade para quem o observa". Este é o que escolhemos apreciar.

A população do bairro é maioritariamente negra. O contraste social é acentuado, de um lado os condomínios e palácios onde funcionam os colégios tradicionais e particulares e, do outro a comunidade composta por casas simples com saneamento básico precário. $\mathrm{O}$ bairro possuiu fortes tradições culturais, conhecido pelo samba que dá movimento às ruas, pelos paladares e aromas da gastronomia baiana, pelas tradições religiosas como a religião católica, o candomblé e, mais recentemente, os evangélicos.

Trabalhamos com uma turma de jovens e adultos do ensino médio no tuno vespertino. A turma era composta por nove estudantes com idades compreendidas entre 21 e 45 anos, que frequentavam o Programa Nacional de Integração da Educação Profissional com a Educação Básica na Modalidade de Educação de Jovens e Adultos, PROEJA.

A escolha dos círculos de cultura para realizar uma proposição educativa com um grupo de estudantes do PROEJA, permitiu-nos realizar um movimento de a ação e reflexão teórica e práxis ao criar uma relação dialógica e reflexiva e, assim, fomentar discussões sobre as diferentes realidades, que de forma hegemônica, continuam a ser negadas pelas práticas pedagógicas conservadoras. O círculo de cultura é caracterizado por Freire (2014a, 1994) como espaço em que dialogicamente se ensina e aprende. Um espaço onde não se transfere conhecimento, mas se produz conhecimento baseado nos saberes, nas experiências, nas histórias de vida do (a) educando (a) e do (a) educador (a). Um espaço que possibilita que cada 
um (a) construa novas hipóteses de leitura de mundo. É um espaço dinâmico que se traduz num processo teórico e prático de pesquisa, vivências e construção coletiva de sabres.

Os círculos de cultura foram desenvolvidos durante um ano letivo, com base no calendário escolar e cada encontro tinha a duração de noventa minutos. Como instrumentos de pesquisa utilizamos entrevistas semiestruturadas e as conversas derivadas dos círculos de cultura que foram gravadas e transcritas. Os textos transcritos foram revisados pelas/os entrevistadas/os o que nos possibilitou retomar aos registros e refletir sobre as informações a serem analisadas. Para a análise e interpretação dos diálogos recorremos à literatura teórica considerada relevante ao estudo crítico dos discursos.

As entrevistas e dos diálogos foram analisados à luz da pesquisa qualitativa por favorecer a "apreensão das "realidades múltiplas", ao recusar a possibilidade de uma realidade unívoca e construída para sempre, esse recurso exercita a pluralidade dialógica já na coleta de informações" (MACEDO, 2010, p. 117). O descortinar das realidades múltiplas viabilizou a análise de um conjunto de opiniões e representações sociais e culturais sobre o tema e, assim, potencializou o foco da investigação.

Ao consideramos o contexto cultural das/os educandos (as) e as trocas simbólicas partilhadas durante a práxis dos círculos de cultura, tornou-se perceptível a aproximação entre os discursos instituídos pela educação e sociedade e os efeitos de sentido por elas produzidos.

Para a analisarmos os discursos recorremos a Verón (1980) que baseia a sua teoria do discurso em dois fundamentos: a produção de sentido está relacionada com as questões sociais e que o fenômeno social é um processo de produção de sentido. "Se o social atravessa as matérias significantes, inclusive a da linguagem, se todo sentido é social, inclusive o produzido pela atividade da linguagem", então o sentido é de natureza social e está em toda a parte (VERÓN, 1980, p. 175). Inerente à produção dos discursos sociais este autor leva também em consideração a questão ideológica, por estarem contidas nas condições de produção dos discursos sociais, assim, como o poder e o que dele deriva nos efeitos discursivos, ou, conforme o próprio autor, às gramáticas de reconhecimento.

O autor considera que no universo social não se reduz, somente, ao ideológico ou ao poder. No seu entender na "rede semiótica, sistemas heterogêneos de determinação se entrecruzam” (VERÓN, 1980, p. 192). O autor esclarece que os significados de 'ideológico’ e 'poder' remetem a dimensões de análise dos fenômenos sociais, e "não as 'coisas' ou ‘instâncias' que teriam um 'lugar' na topografia social”' (p. 192). Isto é, a leitura ideológica ou de poder está presente em um sistema que considera os rituais e comportamentos e, de forma similar, há um agenciamento da gestualidade cotidiana. 
Iniciamos com uma turma de nove estudantes, todos (as) vivem em situações de precariedade de condições materiais de vida. Residem na periferia urbana de Salvador em que o índice de desemprego é um sério problema. O grupo era composto por oito mulheres e um homem. As mulheres se autodefiniram como "negras, pobres, desempregadas". E o homem se autodefiniu como "uma pessoa simples, sensível e acessível a todos." Todos (as) estão desempregados (as) e, a possibilidade de frequentarem a escola depende do apoio familiar. A maioria reside em casa de familiares. Toda a turma comunga de alguma crença religiosa, entretanto, a maioria é evangélica e testemunha de Jeová, umas católicas e nenhuma, declaradamente do candomblé. Com relação ao estado civil, duas são casadas, com filhos e duas solteiras com filhos.

Os primeiros contatos, que antecederam a práxis dos círculos de cultura, iniciaram-se com entrevistas semiestruturadas individuais e coletivas com o objetivo de nos aproximarmos da realidade do grupo e iniciarmos a investigação temática. Após estas conversas iniciais foi decidido, coletivamente, os temas ou palavras geradoras a serem tratadas nos próximos encontros

A partir desse momento, as pesquisadoras delinearam o planejamento dos círculos de cultura de modo sistematizado, mas flexível, com a intenção de contemplar as singularidades de cada participante, possibilitar a partilha de experiências e a construção de conhecimento. Este planejamento possibilitou-nos, ainda, reservar um espaço para que fossem realizadas reflexões críticas acerca dos dados registrados e, assim, sugerir ao grupo outros temas que aprofundavam as questões levantadas durante os diálogos circulares.

Para apreendermos a leitura de mundo dos educandos (as), no decorrer dos círculos de cultura, optamos por utilizar recursos pedagógicos e metodológicos com o objetivo de descortinar e valorizar as experiências corporais e educacionais da vida cotidiana, exteriorizadas pelas falas, silêncios, gestos e mímicas, expressão de sentimentos, entre outras. Esses recursos consistiam na dinâmica de exercícios corporais, momentos de meditação para descontrair, ao mesmo tempo pretendiam fazer emergir significados e discursos encarnados no corpo. Pela leitura de poemas, imagens e vídeos, observamos os conhecimentos prévios do grupo e formulamos, assim, a problematização dos temas a serem debatidos. A escolha destes recursos e a sua concretização nos auxiliaram a refletir para desconstruir conceitos hegemônicos de mitos, tabus sociais, culturais, corporais e sexuais, estruturados em relações de poder que permeiam as vivências e expressões da vida contemporânea.

Cabe ressaltar que esta investigação é parte de um estudo doutoral. Neste artigo nos debruçamos sobre a conceituação dos círculos de cultura de Freire a partir de um dos quatro 
círculos de cultura em que se refletiu sobre questões direcionadas à educação formal, provocadas pelo curta metragem Alike. Como elementos para a reflexão escolhemos as seguintes palavras geradoras educação, criatividade e transformação. Compreendemos que os círculos de cultura podem oportunizar uma práxis educativa transformadora ao oportunizar um fazer pedagógico de perspectiva emancipadora na educação de jovens e adultos.

\section{Círculo de Cultura: uma perspectiva educacional emancipatória}

Freire (1987 2014b) construiu uma reflexão e práxis educativa - por nós considerada práxis pedagógica - que possibilitou desestabilizar e criticar as bases do conhecimento pedagógico hegemônico. Este autor se debruçou sobre propostas de alfabetização para educar, especialmente trabalhadores e camponeses oprimidos. Além disso, o educador efetivou uma proposta pedagógica firmada por uma práxis humanista, na qual os oprimidos se reconhecem como protagonistas da sua educação e da construção dos seus saberes, conhecimentos e cultura. Nas palavras de Arroyo (2014) Freire conseguiu captar a presença e os movimentos populares desses sujeitos e, por isso, tornar a educação um processo de humanização que não tinha a pretensão de instituir um conjunto de métodos, mas 'reeducar a sensibilidade pedagógica'.

Essa reeducação da sensibilidade pedagógica propõe outro caminho para a educação que não se centra no como educar "mas como se educam, nem como ensinar-lhes, mas como aprendem, nem como socializá-los, mas como se socializam, como se afirmam e se formam como sujeitos, culturais, cognitivos, éticos, políticos que são.” (ARROYO, 2014, p. 27). Os círculos de cultura elaborados por Freire partem deste princípio e foram exaustivamente utilizados pelo autor durante o seu percurso de educador.

Assim, compreendemos os círculos de cultura como uma possibilidade pedagógica pertinente para a educação de jovens e adultos ao permitir contextualizar as especificidades e conflitualidades socais, culturais, políticas, históricas, afetivas inerentes a esses sujeitos e possibilitar fazer emergir experiências até então ausentes do cotidiano escolar e da práxis pedagógica.

Nesse contexto, propomos uma reflexão a partir dos círculos de cultura em uma turma do segundo ano do ensino médio - PROEJA com o seguinte tema gerador "Alike: educação, criatividade e transformação". A proposta foi realizada em cinco encontros em que questionamos um fazer pedagógico marcado pela predominância de práticas hegemônicas.

Iniciamos o nosso encontro com o curta metragem "Alike" (2015). Essa animação relata a relação entre um pai e um filho num cotidiano limitado por rotinas impostas. Ora no trabalho, 
ora na escola as normas e convenções sociais instituídas deixam claro um modo de viver padronizado que reprime a criatividade das crianças e dos adultos. Por isso, "Alike" nos convida a resgatarmos os motivos para expressaremos as nossas cores, singularidades, sonhos, criatividades, potencialidades que compõem a nossa humanidade.

Os diálogos e reflexões que surgiram após a visualização do curta metragem direcionaram-se para a experiência educativa e escolar dos (as) educandos (as) que relataram as inúmeras experiências matizadas por várias tonalidades.

Uma das questões abordadas durante o círculo de cultura referiu-se à crítica das pedagogias escolares instituídas por critérios rígidos que não reconhecem a "validade dos saberes, dos modos de pensar e de pensar-se e de educar-se que os educandos levam à escola" (ARROYO, 2014, p. 33).

Compreendemos que a escola está repleta de saberes, tempos e espaços diversificados, no entanto, subordinados a lógicas normativas e formas rígidas que produzem a homogeneização, originando perdas e ausências (SANTOS 1996). Por isso, o ensino e aprendizagem no espaço escola ficam prejudicados ao ser valorizado, apenas, um tipo de saber em detrimento daqueles encarnados nos sujeitos.

Nesta perspectiva de Freire (2014a) aponta a necessidade de que não podemos inferiorizar ou subestimar as mais variadas compreensões de mundo, manifestadas pelos "saberes da experiência feitos" que os educandos trazem consigo e, como indica, negar os saberes que surgem da experiência sociocultural constitui-se em um,

[...] erro científico e a expressão inequívoca da presença de uma ideologia elitista. Talvez seja mesmo o fundo ideológico escondido, oculto, opacizando a realidade objetiva, de um lado, e fazendo, do outro, míopes os negadores do saber popular, que os induz ao erro científico. Em última análise, é essa "miopia" que, constituindo-se em obstáculo ideológico, provoca um erro epistemológico (FREIRE, 2014a, p. 117).

O autor assegura não ser possível fundamentar a práxis educativa somente pelo sensocomum, como também não é possível criar uma práxis educativa que suprima o "saber da experiência feito" e, partir, somente, de um conhecimento sistematizado. A esse respeito a educanda Lara afirmou:

[...] a escola não estimula, não dá abertura para você fazer diferente, tem que seguir um currículo fechado. Na aula de português é importante ter visão dos escritores [...] para mim é difícil, quero escrever a minha história. Na aula de história tenho saber muitas histórias. Preciso aprender, mas eu tenho uma história pra contar, pra escrever é a minha história de vida. 
A educanda Maria acrescenta:

[...] na escola é preciso aprender coisas de várias matérias. Tenho dificuldade, não sei escrever muito. Não sei por que preciso aprender tanta coisa que não usamos na vida. Pra prova decorro e depois esqueço tudo. [...] vendia produtos de beleza, administrava as vendas, na aula não entendo a matemática, as contas.

Certa inflexibilidade pedagógica é destacada pelos (as) educandos (as). Reconhecem a existência de um currículo fechado que não possibilita trabalhar os conteúdos de uma forma mais criativa, no qual seja contemplado outras formas de conhecimento, por exemplo, utilizar a riqueza das experiências de vida com uma maneira de ampliar as perspectivas de mundo.

A esse respeito, Santos (2007b) observa a importância de forjar um conhecimento que considere o conhecimento do cotidiano escolar, social, comunitário, no intuito de potenciar a experiência como um elemento integrante do conhecimento. Para o autor, a emancipação epistemológica e social ocorre quando a expressão do conhecimento-emancipação não se fixa somente na denúncia e, articula a experiência e a interlocução dos vários conhecimentos - a ecologia dos saberes, o conhecimento do senso comum, a solidariedade, a tradução, a ruptura epistemológica (SANTOS, 2007b).

A práxis do círculo de cultura pode possibilitar a expressão do conhecimentoemancipação, pois estabelece uma ligação entre os saberes locais e os conhecimentos universais, com o objetivo de problematizar, refletir e teorizar criticamente as questões que surgem da realidade sociocultural e econômica e, dos conflitos e contradições que permeiam as relações do cotidiano.

O que vamos tentar fazer é um uso contra-hegemônico da ciência hegemônica. Ou seja, a possibilidade de que a ciência entre não como monocultura, mas como parte de uma ecologia mais ampla de saberes, em que o saber científico possa dialogar com o saber laico, com o saber popular, com o saber dos indígenas, com o saber das populações urbanas marginais, com o saber do camponês. Isso não significa que tudo vale o mesmo (SANTOS, 2007b, p. $33)$.

Nesta concepção o saber científico deixa de ser supervalorizado e o senso comum é ressignificado como um conhecimento que possibilita identificar as ausências, potencializar as emergências e promover o diálogo recíproco entre os saberes. Consideramos, assim, que a práxis do círculo de cultura pode potenciar reflexões e ações contra-hegemônicas, ao reconhecer o senso comum e o conhecimento científico como saberes e fazeres credíveis, que não se opõe ao desperdício de experiências de vida e de experiências socioculturais. Ao 
contrário, possibilitam democratizar as relações de poder presentes no cotidiano escolar e a viabilizar outros caminhos para o despontar da emancipação. Como Santos (2002, p. 88-89) argumenta:

A mais importante de todas é o conhecimento do senso comum, o conhecimento vulgar e prático com que no quotidiano orientamos as nossas ações e damos sentido à nossa vida [...] a ciência pós-moderna procura reabilitar o senso comum por reconhecer nesta forma de conhecimento algumas virtualidades para enriquecer a nossa relação com o mundo.

Arroyo (2014) explica que algumas pedagogias escolares coíbem e ignoraram a troca de experiências e interpretações de vida. Por vezes, até tornam o saber e o sentir do Outro como algo inferior, pois o conhecimento está atrelado um padrão de saber dicotomizado pelo poder, dominação/subordinação que impõe práxis educativas predominantemente homogêneas, carregadas de classificações e hierarquizações.

Há uma história de tensões entre pedagogias, no padrão poder/saber, dominação libertação. Essas formas de pensar os Outros estão incrustadas no pensamento educacional. Como crianças, adolescentes, jovens ou adultos populares serão pensados como inferiores ao chegarem às escolas e universidades, ao ser reprovados por com problemas de aprendizagem ou de condutas, valores. [...] Mostram que carregam vivências de opressão segregação, de tratados inferiorizantes. Mostram também como desconstroem as formas como foram pensados e os processos/pedagogias com que foram tratados como inexistentes [...] (ARROYO, 2014, p. 39).

O educando Luan contesta o pensamento que os rotula como inferiores,

A inferioridade vem da diferença que fazem entre a gente. Eu venho da periferia, sou pobre, negro, estudo na escola pública. A escola ensina a ignorar a diferença, o que é muito comum o preconceito. Toda essa opressão que acontece na escola, onde a pessoa que tem o "requisito" mais alto não se dá com o tem mais baixo. A pessoa mais inteligente não quer andar com aquela que tem dificuldade de aprender. $O$ professor não escuta as nossas dificuldades, a nossa história, medos, a pessoa só tem que dominar o saber do livro. E aí onde entra a vida?

A proposta dos círculos de cultura permitiu-nos, pensar numa educação baseada numa práxis comprometida com a transformação social, em que o objetivo central era tornar o oprimido como sujeito protagonista da sua história. Ou seja, uma práxis que possibilitasse aflorar a sensibilidade pedagógica e entender os (as) educandos (as), em situação de opressão, como sujeitos da educação, capazes de partilhar e construir saberes, conhecimentos, valores e cultura (FREIRE, 1987; ARROYO, 2014).

Pensar assim a educação possibilita romper com a compreensão das 'situações existenciais', isto é, entrelaçar a consciência de si mesmo à compreensão de si mesmo no meio 
social, o ser individual e coletivo de Gramsci (2001). O filósofo evidencia a importância de uma pedagogia dialética, na qual o ser individual ao estabelecer uma relação contínua com o ambiente cultural, torna-se "[...] consciente de que a sua personalidade não se limita à sua individualidade física, mas é uma relação social ativa de modificação do ambiente cultural" (GRAMSCI, 2001, p. 400). A transição da classe subalterna à classe hegemônica, assim como da cultura fragmentada à 'unidade cultural-social' é possibilitada quando os interesses particulares são superados. Esse movimento é iniciado no ser individual e por meio da organização da massa de conhecimento cria-se um espaço coletivo que nos incita ao diálogo, autoconhecimento e discussão.

A compreensão crítica de si mesmo é obtida, portanto, através de uma luta de 'hegemonias' políticas, de direções contrastantes, primeiro no campo da ética, depois no da política, atingindo, finalmente, uma elaboração superior da própria concepção do real. A consciência de fazer parte de uma determinada força hegemônica (isto é, consciência política) é a primeira fase de uma ulterior e progressiva autoconsciência, na qual a teoria e a prática finalmente se unificam (GRAMSCI, 2001, p. 103).

Neste sentido, a práxis do círculo de cultura questionou a reprodução de uma educação hegemônica e elitista que contribui para a formação da subalternidade, ao invés de perspectivar a liberdade individual e coletiva, portanto, perspectivar uma outra sociedade. Dentro dessa concepção, as práxis pedagógicas, deveriam compreender o ser humano como inconcluso, imaginativo e curioso, que 'tomando distância' de si mesmo e da vida se interroga sobre a realidade concreta e não determinada por conhecimentos científicos já formalizados.

$\mathrm{Na}$ visualização do curta-metragem Alike a crítica a uma educação hegemônica surgiu com a questão das cores dos personagens, todos cinzentos, absorvidos por uma rotina entediante. A educanda Leila observou a cor cinzenta das personagens e explicou,

Você sabe, tudo igual. Eu já tenho o ensino médio, agora estou no PROEJA e a minha cor está quase apagadinha se apagando, não sinto a relação entre coisas que aprendo aqui e a minha vida lá fora. Na escola tá difícil, o ensino tá difícil. Você tá sentada a olhar pro quadro, a ouvir pró, o ensino tá ultrapassado. Eu já trabalhei, [...] tenho outras experiências, aqui é pra buscar um trabalho melhor [...]. Você sabe quando antes de entrar pra escola era um arco-íris, agora tou verde esbatido, porque aqui e até na vida, na família, lá fora você é mais um. Pra mim o verde é a cor da esperança.

A educanda Nabele, também faz um comentário sobre esse tema,

[...]a minha cor já foi azul da cor do céu, do mar. Mas agora eu não reconheço mais a cor, a gente se esforça, mas somos pressionados pelos professores, a 
gente desmotiva por alguns nem deixam a gente falar, nós temos as ideias mas não são valorizadas é o que está pronto, é muita falta de cor na educação, sabe!

Para contrariar essa lógica hegemônica, no círculo de cultura trabalhamos com temas transversais e abertos, pois na maioria das vezes, os temas debatidos surgem dos "saberes da experiência feitos" dos (as) educandos (as), considerados do senso comum por expressarem saberes culturais, sociais, religiosos e histórias de vida (FREIRE, 2014a). Consideramos que esses saberes enriquecem os diálogos circulares ao serem integrados por uma práxis que não desperdiça as experiências da vida e do processo educativo.

Criatividade, dar outros sentidos e tonalidades ao processo de ensinar e aprender constituiu-se um dos focos desta proposição pedagógica. Quando são percebidas as situações limite o que nos oprime e, passamos a ter consciência do percebido-destacado o ser humano encontra um incentivo para agir em busca do inédito viável (FREIRE, 2014a).

A busca pelo 'inédito viável' possibilita-nos aceder a um processo criativo, de criação, recriação, invenção, reinvenção, pois segundo Freire (2014b), a ação criativa do sujeito expressa-se pela sua maneira de ler o mundo. Para o autor a criatividade e a ação criativa estão relacionadas com a práxis problematizadora, expressa por uma concepção de educação que instiga um pensar, sentir, agir consagrado pelo processo de libertação de ações domesticadoras, as quais coisificam o sujeito.

Daí surge a 'criatividade libertadora' como condição humana, a qual fomenta um estado de consciência crítica e se expressa pela capacidade de um sujeito singular e inconcluso criar, agir e transformar a realidade. $\mathrm{O}$ curta Alike sugere uma busca criativa para transformarmos a nossa realidade. Neste ponto, Luan argumenta:

[...] fazemos tudo no automático, como no vídeo, vamos pra escola, no trabalho com cara cansada, um tédio, sem cor. As coisas não vão bem, mas não paramos pra pensar e buscar outra forma de resolver a nossa situação. $\mathrm{Me}$ vejo como alguém que pertence às artes em geral, sou um bom escritor, não pra qui (escola). Quero escrever sobre a questão da droga, prostituição realidade que conheço. Eu já escrevi uma peça de teatro. Quero aprender mais sobre escrita e desenvolver esse meu lado criativo.

Maria continua o diálogo:

[...] sou criativa a resolver os problemas da vida, são muitos, muito sofrido [...]. Sempre precisei de dar um jeito, como o pai do menino que começou a imitar o homem que toca violino, procuro a minha cor, colorir meus estudos colorir a minha família. A escola precisa de estar mais aberta para as diferenças. Fazer atividades e encontros como estes, porque a gente precisa de conversar sobre estas coisas pra viver melhor. 
Reconhecemos que a educação não é neutra (FREIRE, 2014a; SANTOS, 1996). Ela estabelece uma relação com o mundo e possibilita-nos uma práxis que busca por uma libertação autêntica - a humanização - a qual nos remete para a o 'ser mais'. Nesta práxis, homens e mulheres são vistos como seres inacabados e, ao mesmo tempo integrais, que se reconstroem ao longo da história, recriam a sua existência ao longo da vida, por meio do trabalho, dos conflitos, do amor, na convivência com o outro, é neste movimento, nesta busca incessante que o ser humano se lança na aventura de se conhecer e de ser mais (FREIRE, 2014a). Para esta perspectiva, a educação deverá estimular meios criativos e alternativos para uma busca emancipadora que se fundada numa atitude crítica e comprometida com a práxis.

Freire (2014a) considera a educação como um 'que fazer permanente' que possibilita o emergir da consciência se torne um processo contínuo e permanente, o qual envolve crítica e autocrítica na elaboração de conhecimento É na travessia desse processo que mulheres e homens vivem uma permanente tensão entre a humanização, ser mais e, a desumanização, ser menos, a primeira considerada como vocação humana e a segunda a distorção da vocação. A vocação de ser mais só se concretiza quando as injustiças, as explorações, as opressões, as violências forem substituídas pelos fundamentos da liberdade e justiça, possibilitando, assim, a recuperação da humanidade daqueles que se encontram oprimidos, conforme anuncia o autor:

[...] se admitíssemos que a desumanização é vocação histórica dos homens, nada mais teríamos que fazer, a não ser adotar uma atitude cínica ou de total desespero. A luta pela humanização, pelo trabalho livre, pela desalienação, pela afirmação dos homens como pessoas, como "seres para si", não teria significação. Esta somente é possível porque a desumanização, mesmo que um fato concreto na história, não é, porém, destino dado, mas resultado de uma "ordem" injusta que gera a violência dos opressores e esta, o ser menos. (FREIRE, 1987, p. 30)

Durante a visualização do "Alike" e posterior reflexão sobre uma educação hegemônica, procuramos entender a tensão entre humanização e desumanização existente na vida em geral. Consideramos que essas tensões provêm da visão determinista do processo histórico que nos remete para a indiferença face ao sofrimento e violência provocados pelo domínio da exploração capitalista. Esta situação desumana leva-nos a pensar que estamos submetidos a uma espécie de destino implacável que anula a nossa consciência, criatividade e vontade de transformar.

Nas palavras de Santos (1996), ao ser desvalorizado o passado em benefício de um futuro supostamente radioso, o tempo presente acaba por ser acometido por uma permanente a "banalização" e a "trivialização" do sofrimento humano e dos conflitos socioeconômicos e 
políticos. Consequentemente, essa "trivialização traduz-se na morte do espanto e da indignação. E, está na morte do inconformismo e da rebeldia" (SANTOS, 1996, p. 16). Daí o grande desafio para a construção de uma educação emancipatória seja o de revelar a conflitualidade do passado, por meio de imagens desestabilizadoras e, "recuperar a capacidade de espanto e de indignação e orientá-la para a formação de subjetividades inconformistas e rebeldes" (SANTOS, 1996, p. 17).

Autores como Freire (2014a), Santos (1996) e Arroyo (2014) deixam claro que é preciso compreender a complexidade histórica para que não fiquemos submetidos a determinações hegemônicas, aprisionados por parâmetros teóricos sobre a compreensão do ser humano no mundo. A ideia central dos autores é tomar a complexidade histórica como uma possibilidade de construção humana, de conceber outras formas de ser e estar no mundo e de organizar a cultura e as instituições. Complexidade essa que se traduz em um desafio para uma educação que aponte novas alternativas para a existência humana.

Esta conflitualidade do passado convida-nos a pensar o presente de forma crítica, manifestado pela experiência de decisão, de ruptura e, também, por um estímulo à conflitualidade de conhecimentos que não se esgotam numa só visão, mas sim na diversidade de formas de conhecer protagonizadas pelos diferentes grupos sociais (SANTOS, 1996).

No contexto destas ideias, apontamos ser essencial que uma educação emancipatória reinvente outros processos de racionalidade. Outra racionalidade, isto é, um conhecimento útil e comprometido com as questões e os problemas da sociedade atual.

Santos (2007b, p.25) evidencia que um dos entraves para o exercício de uma educação emancipadora é provocado por uma forma de raciocínio, por ele denominado de "[...] razão indolente, preguiçosa, que se considera única, exclusiva, e que não se exercita o suficiente para poder ver a riqueza inesgotável do mundo." Essa "razão indolente, preguiçosa" é expressado por um conhecimento reducionista, linear, simétrico, pautado por um sistema hierárquico que causa distintos processos de "estar fora", cria formas de "não existência" e "de ausências" (SANTOS, 2007b). Sobre o “estar fora” Evely argumenta:

Eu nunca me senti valorizada, o meu saber aqui não conta, a minha experiência da vida muito menos. Sou negra, baiana, pobre e da periferia. Não sei muita coisa da escola, mas sei que isso da minha origem não ajuda agente chegar onde quer chegar.

Como alternativa a uma racionalidade preguiçosa propõem-se novas possibilidades de criar práxis educacionais que objetivem vivências criativas e transformadoras, isto é, fazer com que a diversidade da realidade que está ausente nos contextos educativos se torne presente, "o 
que está ausente esteja presente, que as experiências que já existem mas são invisíveis e não críveis estejam disponíveis; ou seja, transformar os objetos ausentes em objetos presentes" (SANTOS, 2007, p. 32). Leila acompanha esta ideia:

[...] transformar, não fazer igual, agente já viu que não dá certo. A educação tá aí pra nos abrir pro mundo e pra nós mostramos o nosso mundo, as nossas cores, as nossas experiências. A gente precisa aprender a ouvir, a gente pensa que somos diferentes no final quando cada um fala mostra o que todos aqui sentimos medo, frustração, raiva. Todo o mundo tem obstáculos, a gente passa por trancos e barrancos... Mas temos a esperança!

Entendemos os círculos de cultura como uma alternativa aos modos de racionalidade hegemônicos, ao se constituírem em espaços que permitem anunciar a invisibilidade e, assim, denunciar as desigualdades, exclusões e opressões potenciadas por dinâmicas de dominação social. São um espaço de encontro, no qual dialogicamente se ensina e aprende, em vez da justaposição ou da superposição de conhecimento, constroem-se saberes, permitindo que os educandos elaborem os seus pressupostos de leitura do mundo (FREIRE, 2014a).

Ao longo do texto, trouxemos as vozes dos educandos (as) e autores com o intuito de reforçar a práxis do círculo de cultura como uma possibilidade educacional emancipatória capaz de resgatar as experiências ausentes e negadas por uma escola composta, na maioria das vezes, por uma estrutura rígida, subordinada a uma cultura dominante que não reconhece outros modos culturais de pensar, agir e sentir.

A práxis do círculo de cultura nos sugere transformação, um modo criativo de fazer educação, o qual possibilitou os educandos (as) educandos (as) a expressem as suas leituras de mundo e, principalmente, ocasionar a oportunidades de escuta e elaboração de novas sínteses.

\section{Considerações finais}

Neste artigo nos propusemos pensar a vida e a educação por meio de uma lógica diferenciada do que está posto hegemonicamente no fazer pedagógico de uma escola pública situada em um quilombo urbano de Salvador, Bahia, Brasil. O lugar considerado, para além do princípio do espaço geográfico, é o do espaço antropológico, considerado como espaço existencial, ou seja, um lugar relacional do ser humano com o mundo e com os outros, situado e relacionado a seu meio.

Para tal, nos baseamos na teoria e na práxis educacional desenvolvida pelo educador brasileiro Paulo Freire, especialmente em seus escritos sobre os círculos de cultura como práxis, bem como a proposta de, ao renovar a teoria crítica, reinventar a emancipação social. Ao fazer 
isso ousamos pontuar a práxis dos círculos de cultura como uma proposição epistemológica que cria conhecimentos, práxis e saberes outros, considera o universo e os conhecimentos dos sujeitos da história, no caso os estudantes do PROEJA de uma escola de salvador localizada em um território de quilombo urbano na parte central da cidade.

Recorremos, para tal, à visualização e reflexões sobre questões levantadas pelo curtametragem "Alike". Estas utilizadas como estímulos para desconstruir conceitos hegemônicos estruturados por relações de poder que permeiam as vivências e expressões educativas e pedagógicas do cotidiano escolar. A escolha dos círculos de cultura se tornou, assim, uma alternativa pedagógica potente para a transformação do fazer pedagógico hegemônico para uma práxis outra, diferente e transformadora. Esta práxis proporcionou o compartilhar de histórias, fragmentos de histórias de vida dos educandos e educadoras, experiências do cotidiano e visões de mundo definidas como 'simples' e amplia-las para uma práxis consciente e crítica da realidade, de si mesmo e das possíveis relações do conhecimento e do mundo.

Esta proposta oportunizou, nas palavras de Luan, "um conhecimento de mim mesmo e ampliou a minha consciência. Quando mudo internamente a minha ação no cotidiano, na sociedade é diferente, mais consciente das relações, política, cultura, economia, que me estão envolvendo e me influenciando.” E realizar uma crítica à postura reprodutiva e reducionista da escola e de determinados conteúdos e conhecimentos, de como eles são repassados e de como eles contribuem para a formação da subalternidade, ao invés de perspectivar a liberdade individual e coletiva, portanto, perspectivar uma outra sociedade.

Com efeito, os círculos de cultura são compreendidos como práxis e, portanto, não apenas como uma possibilidade metodológica e/ou didática, mas sim, como um conjunto de indicações teórico-metodológicas que permitem reconhecer a visão de mundo, a realidade concreta e reinventar outras formas de construção de conhecimento. Por tudo isto, os consideramos como uma práxis que tende à emancipação, pois o (a) educando (a) é o protagonista do seu processo de conhecimento, é um sujeito ativo que participa de forma crítica e criativa em todas as dimensões da vida social. As relações estabelecidas entre educandos e educadores tornam-se mais horizontais e solidárias, ou seja, não existe sobreposição e hierarquização entre os sujeitos e os seus respectivos saberes. Além disso, importa considerar que esta práxis situada é uma práxis afetiva, em que o (a) educando (a) e o (a) educador (a) se tornam seres humanos plenos e integrais, nas palavras de Gramsci, omnilaterais, ou seja, dotados de sentimentos, emoções, razões, seres que aprendem a sentir, escutar, sensibilizar, conhecer, refletir, intervir e recriar o próprio ser, consequente e conscientemente, as relações cotidianas e o mundo. 


\section{REFERÊNCIAS}

ALIKE. Direção: Daniel Martinez Lara e Rafa Cano Méndez. Produção: Daniel Martinez Lara. Produtora: Pepe School Land. Local: Espanha. Duração: 8 minutos. Disponível em: https://www.youtube.com/watch?v=UATPH44jRSw. Acesso em: 10 mar. 2017.

ARROYO, Miguel. Outros sujeitos, outras pedagogias. 2. ed. Petrópolis, RJ: Vozes, 2014.

AUGÉ, Marc. Não lugares: introdução a uma antropologia da supermodernidade. 9. ed. Campinas, SP: Papirus, 2012.

FREIRE, Paulo. Pedagogia do oprimido. 17. ed. Rio de Janeiro: Paz e Terra, 1987.

FREIRE, Paulo. Cartas a Cristina. Rio de Janeiro: Paz e Terra, 1994.

FREIRE, Paulo. Educação como práxis da Liberdade. 27. ed. Rio de Janeiro: Paz e Terra, $2014 b$.

FREIRE, Paulo. Pedagogia da Esperança: um reencontro com a pedagogia do oprimido. 21. ed. São Paulo: Paz e Terra, 2014a.

GADOTTI, Moacir. Educação e poder: introdução à pedagogia do conflito. 1. ed. São Paulo: Cortez, 2003.

GRAMSCI, Antonio. Cadernos do Cárcere. Tradução de Carlos Nelson Coutinho com a colaboração de Luiz Sergio Henriques e Marco Aurélio Nogueira. Rio de Janeiro: Editora Civilização Brasileira, C. 1, C. 10, 2001.

LIMA FILHO, Domingos. O PROEJA em Construção: enfrentando desafios políticos e pedagógicos. Universidade Federal do Rio Grande do Sul Porto Alegre, Brasil. Rev.

Educação \& Realidade, v. 35, n. 1, p. 109-127, 2010.

MACEDO, Roberto Sidnei. Etnopesquisa crítica, etnopesquisa-formação. 2. ed. Brasília: Líber Livro Editora, 2010.

SANTOS, Álvaro. O blog do bairro Fazenda Garcia. Disponível em:

https://fazendagarcia.wordpress.com/2007/11/17/a-historia-do-bairro-fazenda/, 2007a. Acesso em: 10 jan. 2017.

SANTOS, Boaventura de Sousa. Para uma pedagogia do conflito. In: SILVA, Luiz Eron da. Reestruturação Curricular: novos mapas culturais, novas perspectivas educacionais. Porto Alegre: Sulina, 1996.

SANTOS, Boaventura de Sousa. Renovar a teoria crítica e reinventar a emancipação social. São Paulo: Boitempo, 2007b.

SANTOS, Boaventura de Sousa. Para um novo senso comum: a ciência, o direito e a política na transição paradigmática. 4. ed. São Paulo, Cortez, 2002. 


\section{Como referenciar este artigo}

VIEIRA, Joana Lopes.; SILVA, Maria Cecília de Paula. Os círculos de cultura como possibilidade pedagógica na perspectiva da emancipação: uma experiência no PROEJA de uma escola pública de Salvador - BA, Brasil. Revista Ibero-Americana de Estudos em Educação, Araraquara, v. 14, n. 2, p. 601-619, abr./jun., 2019. E-ISSN: 1982-5587. DOI: 10.21723/riaee.v14i2.11486

Submetido em: 19/06/2018

Aprovado em: 20/10/2018 